\title{
Having their Say: \\ Authority, Voice, and Satisfaction with Democracy ${ }^{12}$
}

\author{
*****Forthcoming in the Journal of Politics***** \\ Eric Merkley ${ }^{3}$ \\ Ph.D. Candidate \\ Department of Political Science \\ UBC - Vancouver \\ Email: eric.merkley@alumni.ubc.ca \\ Address: 1866 Main Mall - C425 \\ Vancouver, BC, Canada V6T 1Z1

\section{Paul J. Quirk \\ Professor} \\ Department of Political Science \\ UBC - Vancouver \\ Email: paul.quirk@,ubc.ca \\ Address: 1866 Main Mall - C425 \\ Vancouver, BC, Canada V6T 1Z1 \\ Fred Cutler \\ Associate Professor \\ Department of Political Science \\ UBC - Vancouver \\ Email: fred.cutler@ubc.ca \\ Address: 1866 Main Mall - C425 \\ Vancouver, BC, Canada V6T 1Z1 \\ Benjamin Nyblade \\ Director \\ Empirical Research Group \\ UCLA School of Law - Los Angeles \\ Email: nyblade@law.ucla.edu \\ Address: 385 Charles E. Young Dr. \\ Los Angeles, CA, 90095
}

\footnotetext{
1 Data and supporting material necessary to reproduce the results are available in the JOP dataverse (https://dataverse.harvard.edu/jop/). Research was conducted in accordance with guidelines set by the UBC Behavioural Research Ethics Board. Support for this research was provided by the Social Sciences and Humanities Research Council of Canada as part of the Making Electoral Democracy Work (MEDW) research program and by the University of British Columbia Vice-President Research and Innovation.

${ }^{2}$ We would like to thank Spencer McKay and five anonymous reviewers and for their challenging comments that helped improve the paper considerably. Thank you as well to the Sierra Club of Canada and its Executive Director John Bennett for their participation in this study. Replication materials and the supplementary appendix can be found on the author's website (https://ericmerkley.com/publications).

${ }^{3}$ Corresponding author.
} 


\begin{abstract}
As studies using macro-level evidence have shown, citizens are more satisfied with democracy when they feel that their instrumental preferences are represented in government, and this feeling is more likely in non-majoritarian institutional contexts. Scholars have given less attention to whether such institutions also increase satisfaction by providing more inclusive political discourse. Citizens may value having their voice represented in politics, regardless of the resulting authority. This paper presents the first micro-level evidence of this mechanism by having subjects experience a simulated election campaign that manipulates both the political discourse and the outcome independently. We find that subjects were less satisfied with democracy when their party lost the election; but this effect disappeared when the campaign discourse had featured thorough discussion of an issue they felt was important. The findings suggest that institutions and party systems that provide more diverse voices may soften the blow of losing elections.
\end{abstract}


What makes a good democracy? What makes democracy good? A genuinely democratic answer to these questions looks to citizens themselves for answers. It turns out that citizens' satisfaction or dissatisfaction with the way their democracy functions is based in multiple, sometimes conflicting considerations. Macro-oriented scholars have enumerated many of these features (Diamond 2005) and macro-measurement at the country level is now very rich (e.g. Bühlmann, Merkel, Müller, and Weßels 2012). We know much about the institutional and contextual influences on citizens' responses to the "satisfaction with the way democracy works in their country" survey question (Anderson et al. 2005). Yet, most evidence is at the aggregate level and has a 'black box' quality. This is true even of studies where individual-level data is used, because the macro factors of interest for scholars, by definition, do not vary within a country. ${ }^{4}$ More micro-level evidence is needed on the mechanisms that transmit institutional and contextual factors through to citizens' satisfaction. The present paper speaks to the effect of the character of political discourse on satisfaction with democracy.

Scholars have been curious about the institutional and contextual influences on satisfaction with democracy partly because some of these influences may be manipulated by constitutional, political or even social means, but also because satisfaction with democracy is commonly taken as one measure of the quality of a democracy. However, one individual-level attribute relating individuals to their political context dominates the literature: supporting a party or candidate that wins the election, which creates Anderson et al.'s “Winner-Loser Gap” in satisfaction with democracy (2005; see also Berggren et al. 2004; Bernauer and Vatter 2011; Curini, Jou, and Memoli 2012). The power of this variable is intuitive, as citizens naturally prefer governments that share their preferences. Singh, Karakoç, and Blais (2012) conclude that the "inclusion of one's selected party in government is the most important

\footnotetext{
4 There are a few notable exceptions to be discussed below (Chang, Chu, and Wu 2014; Curini Jou, and Memoli 2012, 2015; Singh 2014).
} 
factor for satisfaction with democracy, which attests to the importance of policy considerations in engendering satisfaction."

It is not surprising, then, that the dominant focus of the literature has been on how "consensus institutions" (ones that promote governments composed of multiple parties commanding majorities of the popular vote) and other factors that temper the power of a one-party majority - which we call 'non-majoritarian institutions' - can cushion the blow of losing and produce electoral losers who are less dissatisfied relative to winners (Anderson and Guillory 1997; Banducci and Karp 2003; Bernauer and Vatter 2011; Blais and Gélineau 2007; Esaiasson 2011; Henderson 2008). The most obvious reason for this is that losing voters in these systems expect policy to be closer to their preferences than do losing voters in majoritarian polities. Research establishing the micro-level mechanisms that link non-majoritarian institutional forms to satisfaction with democracy has been limited, but key findings have emerged that highlight the importance of ideological congruence between citizens and governments (Curini, Jou, and Memoli 2012, 2015) and strategic voting (Singh 2014) in determining the extent of the winner-loser gap. ${ }^{5}$

Evidence also points to important non-policy considerations that affect the winner-loser gap, such as the emotional effects of one's party losing repeatedly or perpetually (Chang, Chu, and Wu 2014; Curini, Jou, and Memoli 2012, 2015). One other possible non-policy mechanism to shrink the winnerloser gap may involve features of non-majoritarian institutions that are valued by many normative theorists - the richer, more inclusive political dialogue in countries with non-majoritarian institutions. The idea is that when more, often smaller, parties are involved, more issues relevant to a greater

\footnotetext{
5 Golder and Stramski (2010) find that non-majoritarian systems only outperform majoritarian systems in congruence between legislatures and citizens, not between governments and citizens, suggesting that the strictly instrumental policydistance minimization mechanism may not entirely explain higher levels of satisfaction in non-majoritarian systems.
} 
proportion of the populace get discussed. Could it be, then, that citizens value certain features of political dialogue independent of policy considerations?

In this paper, we provide the first experimental micro-level evidence of a key non-policy mechanism that may help explain why losers in consensus or non-majoritarian democracies are more satisfied with democracy than their majoritarian counterparts. To be clear, ours is a test of a plausible mechanism for a link between institutions and satisfaction with democracy; we take from the literature that such a link exists and do nothing to test it. We use an experimental design to examine the effect on subjects' satisfaction with merely hearing their position on important issues articulated, independent of winning or losing. We hypothesize that whatever the outcome of an election and the identity of the resulting government authority, when citizens hear elite, mediated political discussion reflecting their positions on issues they care about, they will be more satisfied with the way democracy works than when there is silence on that issue. If we can show this, and it is accepted that consensus institutions have more wide-ranging and inclusive political dialogue, then we will have established one important way in which institutions affect satisfaction with democracy. In addition, our results imply that other institutions that affect the inclusiveness of political discourse -- not just electoral systems may also have important effects on satisfaction with democracy.

The paper begins by summarizing the relevant theory and findings in the literature and focusing our theoretical lens on the distinction between voice and authority. Then we describe the experimental design and provide the results from two very different sets of subjects. We conclude with a discussion of the implications of our findings, which strikingly reinforce what has been found in cross-national survey research. 


\section{Authority, Voice, and Democratic Satisfaction}

Theorists have drawn attention to authority and voice as key concepts in their efforts to describe and understand democratic representation (Warren 1996). It is natural to think that these might be two key mechanisms through which the context of elections and political discourse can influence citizens' judgments of the quality of their democracy.

Citizens are concerned that their preferences are represented in the formal process through which authoritative decisions are made. It follows that authority is one important dimension that produces the winner-loser gap in voters' satisfaction with democracy (Anderson et al. 2005; Han and Chang 2016; Singh, Karakoç, and Blais 2012). Individual citizens will be more satisfied when the electoral process results in the installation of those who share their policy preferences in positions of authority. The extensive literature linking winning and losing to citizens' satisfaction shows that voters who supported the winning party or candidate are more satisfied than those who supported the losers and that the latter are more satisfied in consensus and non-majoritarian systems. The typical explanation for both findings is that in each case they reflect greater satisfaction resulting from lesser distances between citizens' policy positions and the governments' (e.g. Curini, Jou, and Memoli 2012; Ezrow 2007; Singh, Karakoç, and Blais 2012), though there may be non-policy reasons as well (Chang, Chu, and Wu 2014; Curini, Jou, and Memoli 2012, 2015). All else equal, then, election winners will be more satisfied than election losers:

Authority (Hypothesis 1): Citizens whose preferred party or candidate wins an election will be more satisfied with democracy than candidates whose party or candidate loses, all else equal.

However, if authority and its policy outputs were all that mattered to citizens, many institutional and cultural features of democracies might have little or no effect on satisfaction, or thus on the quality of democracy. Only those institutions that affected the composition, duration, and policy products of governments affect satisfaction. But normative theorists and social commentators have long 
advocated various discourse-based solutions to citizens' dissatisfaction with their democratic system (Chambers 2003; Cohen 1989; Habermas 1996). In the most recent summative work in democratic theory, Warren argues that "empowered inclusion" and "collective agenda and will formation" join "collective decision-making" as "functions necessary for a political system to work democratically" (2017, 46). He identifies "recognition", "deliberation", and "representation" as among the "generic practices that serve democratic functions". We suggest that in mass democracies with a complex field of electoral and non-electoral representation (Kuyper 2016), the voicing of political positions and agenda-preferences, as well as "representative claims" (Saward 2006) by many actors in the system, all contribute to a citizen's evaluation of the degree and quality of recognition, deliberation, and representation in the polity.

One component of an empirical theory corresponding to some of this normative work would be, then, that the more wide-ranging (in terms of issues) and more inclusive (in terms of actors) political discourse is in a polity, the more citizens will feel that their claims are being made. Because of this, they will feel adequately represented and they will judge their democracy more positively. Importantly, this mechanism from discourse to democratic satisfaction can operate independently of the distribution of influence on collective decision-making. ${ }^{6}$ And this is the mechanism that is the subject of this study: Are citizens who are exposed to a more diverse and inclusive elite political dialogue more satisfied with the system overall? If we show this, then scholars who may show more diverse, inclusive dialogue in different political systems can more confidently link this institutional variation to citizen satisfaction and democratic quality.

\footnotetext{
${ }^{6}$ Though we acknowledge that the two can be positively correlated such that louder, privileged voices can wield undue influence on decisions
} 
Legislatures in democratic systems fall short of deliberative democratic ideals with respect to the inclusiveness of discourse. The political discourse carried in the mass media, particularly at election time, is likely to fall even further short. Reasonable counter-arguments, signals of mutual respect, and efforts at consensus building rarely survive the conflict and drama-laden biases of parties and the press (Bennett 1988). But there are strong theoretical reasons to suspect the media tend to reflect the general parameters of elite debate (Althaus 1996), and that this debate is richer in less majoritarian systems (Steiner et al. 2005). More relevant for our purposes, such debate is likely to be more inclusive. Majoritarian electoral systems tend to produce two major brokerage parties and, only sometimes, third or fourth minor parties that get much less media coverage (Lijphart 1999). By contrast, nonmajoritarian systems, because they usually feature more parties that are given a voice by the mass media, are more likely to feature prominent issue-specific or niche parties that can more credibly speak to their issues than can brokerage parties in majoritarian systems (Nyblade 2004; Stoll 2008).

But it is not just electoral systems that have implications for voice. Other variations in institutions and laws within both majoritarian and non-majoritarian settings also matter. For one, institutional reforms that facilitate the election of women or racial and ethnic minorities can presumably lead to more vocal substantive representation of historically disadvantaged groups, including in electoral discourse (Preuhs and Juenke 2011; Washington 2012). For another, changes to party nomination processes have been essential to getting more women elected to public office, and some evidence suggests female legislators more actively take up women's issues (Celis 2006). Non-electoral institutions and laws can be just as important. Campaign finance laws may have considerable influence on patterns of interest group politics. If such laws are too tight they may crowd out the influence of third parties on elections that can provide essential voices to groups and interests not adequately represented by traditional political parties; if too loose they may allow already dominant voices, like those of the wealthy and corporate interests, to drown out those of disadvantaged groups (Gilens 
2015). A wide array of institutions have implications for voice, so we should learn more about how citizens react to more or fewer voices in political discourse.

So we add to "authority" a second possible mechanism that connects political context to democratic satisfaction: voice. The concept of voice has been largely glossed over in previous empirical literature on satisfaction with democracy. For Mark Warren, and for our purposes here, voice exists when individuals have "authoritative standing as speakers in deliberative contexts" and are owed responses to their claims and arguments $(1996,50){ }^{7}$ Of course, in a mass democracy most citizens do not expect to be heard and acknowledged personally in political discourse, but they may desire their voice to be represented in these ways. ${ }^{8}$ That is, we may expect a citizen to be more satisfied with democracy to the extent that political actors articulate her positions on issues she thinks are important and that those positions are taken seriously by other players in the political process. ${ }^{9}$ In short, citizens want to

${ }^{7}$ As Warren $(1996,2017)$ notes, for people to have voice it is not sufficient for their representatives to simply exist and voice their concerns, these concerns and arguments have to be acknowledged by other actors in a deliberative setting. Although political discourse in the media is far from deliberative, there is variation on the degree to which issue representatives can effectively shape elite debate. This is addressed in our experimental design by having the key issue important to subjects appearing at the center of inter-party debate during the course of the simulated election.

${ }^{8}$ Recent work by Reher (2014) has shown that issue salience congruence between citizens and elites is related to satisfaction with democracy. We suspect this is likely the case, particularly on performance-based issues. But, for a citizen's voice to be heard on many of the directional issues that dominate policy it requires more than salience alone - their issue positon needs to be reflected as well. It is likely not always sufficient for representatives to simply bring issues to public attention for citizens to feel like they have voice.

${ }^{9}$ Some actors will more credibly speak to certain issue positions than others. For example, we know that political parties “own” issues based on their respective voter coalitions (see Budge and Farlie 1983; Petrocik 1996; Petrocik, Benoit, and Hansen 2003). Citizens will only feel like their voice is adequately represented on an issue if that representative has credibility on an issue, such as parties that stake their reputation on advancing certain issues or interest and advocacy groups dedicated in their mission to advance certain causes. In this way, they can effectively guard against "cheap talk." 
be heard, even if it is usually others who do the talking on their behalf (Saward 2006). Our experiments speak specifically to these ideas about mediated expression of demands in contrast to tangible forms of representation in government authority. This forms the basis of our second hypothesis:

Voice (Hypothesis 2): Citizens will be more satisfied with democracy when their positions on issues they care about are articulated in political discourse.

To be sure, scholars have suggested that voice may matter, but the distinction between voice and authority is rarely made clearly in the literature on democratic satisfaction. The seminal piece in the satisfaction literature, by Anderson and Guillory, argued that the effects they observed were a result of opportunities for voice and policy-making, bound together: "Given that consensual systems provide the political minority with a voice in the decision-making process, we expect that the more consensual the set of political institutions in a country, the greater is the extent to which negative consequences of losing elections are muted" (1997). Voice as conceived here is not mere voice, independent of authority, but rather a voice in authoritative decisions, and this is consonant with much democratic theory as well (Fung and Wright 2003; Dryzek 2010).

Given the theory cited above, however, it is plausible that citizens are concerned with having their voice heard regardless of their relationship with the current government and that this may well matter more for supporters of parties out of government. Winners, after all, are reasonably confident their voice will matter in government. Consistent with this conceptualization of voice, Anderson et al. (2005) and Ezrow and Xezonakis (2011) point to the importance of opportunities for voice for losers, both electoral and representational. Anderson (2012) eventually came to argue, years later, that: “a more numerous and differentiated [electoral] supply reduces the negative impact losing has on system

We ensure this condition is met in our design by having issue positions represented by either interest groups or political parties explicitly dedicated to the issue. 
attitudes because it provides the next best thing to winning outright: having one's political voice articulated clearly and visibly." There is also indirect evidence for the importance of voice in Aarts and Thomasson's (2008) finding that citizens' views on the quality of representation are a more powerful determinant of democratic satisfaction than their views about whether voting "makes a difference." For their part, Ezrow and Xezonakis also suggest that voice is important even in the absence of authority. They find that "diversity of party alternatives" is positively linked to democratic satisfaction because parties "voice citizen demands for policy” (2011, 1153). Ezrow and Xezonakis quote Sartori to the effect that: "Parties are channels of expression... They are an instrument, or an agency, for representing the people by expressing their demands" $(1976,27)$. This leads to our third hypothesis:

Voice X Authority (Hypothesis 3): The effect of hearing issues they care about articulated on citizens' satisfaction with democracy will be greater for citizens whose preferred parties fail to win positions of authority than for citizens whose parties win authority.

\section{Study Design and Protocol}

We conducted web-based experiments on two sets of subjects where the manipulation involved the presentation of a simulated election campaign with important differences in the issue content and the identity of the actors articulating those issues across conditions. Our experiments were conducted in Canada, which couples a Westminster parliamentary democracy with a single member plurality electoral system. Although such a system is broadly majoritarian, Canada's relatively decentralized federalism with variation in party systems across provinces may provide more avenues for voice than otherwise comparable centralized systems. Most importantly for our study design, Canada is one place where we can add voices and parties as manipulations that will be credible to experimental subject- 
voters. The simulated election was described as occurring not in the Canadian subjects' own province but rather in another province - Manitoba - that few, if any, subjects would follow in the news. ${ }^{10}$

The experimental protocol was as follows. First, each subject completed a pre-treatment questionnaire including demographics and general political attitudes. Subjects were then given a preamble, explaining that they would read news articles about an election campaign in Manitoba, would be asked some questions about it, and would be able to cast a vote for their preferred party.

Second, subjects read eight newspaper articles in a set sequence. Articles were carefully formatted to look like actual newspaper articles. They were written by a former political journalist using real Manitoba election articles as a model. An example can be found in Figure 1 and the text of the others are in the online appendix. Five articles covered events or appearances in which party leaders, candidates, and other actors expressed policy positions on one of four issues: work-for-welfare, the minimum wage, crime, and, depending on the condition, either the treatment issue or the control issue. Policy positions were quite specific, reflecting the content of the real articles on which they were modeled. A critical feature of the development of these materials was the formulation of policy positions reflecting the appropriate ideological locations of the parties for the given treatment shown in Figure A15 in the Appendix. For example, in the environmentalist three-party condition, each article needed a left-wing (advocacy groups), centre-left (New Democrat), centre-right (Liberal), and right-wing (Conservative) policy position. The two final campaign articles summarized the parties' policy differences, one reporting on a party leaders' debate, the other giving a pre-election summary of the campaign. Subjects then indicated how they would vote in this election and received an article that informed them of the election result.

\footnotetext{
${ }_{10}$ We excluded respondents who had lived there in the past 20 years. These were $1 \%$ of our student subjects and $3.4 \%$ of our environmentalist subjects.
} 


\section{Election Battleground: Minimum Wage}

\begin{tabular}{|c|c|c|}
\hline By Kathy Gannon & "Our plan ensures the minimum wage will increase & He said the Conservative Party supports tax relief for \\
\hline $\begin{array}{l}\text { The Liberals and NDP were out to make a big splash } \\
\text { Monday as both promised to hike the minimum wage. } \\
\text { Liberal leader Jon Gerrard made his announcement } \\
\text { early yesterday morning, pledging his party would raise } \\
\text { the minimum wage rate from } \$ 8 \text { to } \$ 9 \text { if elected. } \\
\text { "Students and families need the money," he said at a } \\
\text { downtown press conference. "After years of waste and } \\
\text { neglect by this NDP government, which has allowed } \\
\text { taxes and tuition to increase, it's time for hardworking } \\
\text { Manitobans to get a raise." } \\
\text { Gerrard said the increase would boost consumer } \\
\text { spending and help expand the province's economy. } \\
\text { One employee, Sonja Borton, has been working } \\
\text { minimum wage jobs for over } 30 \text { years. } \\
\text { "An extra \$1 an hour would help me out a lot. Prices } \\
\text { keep going up for food and clothing and for rent, but } \\
\text { wages don't go up at all," she said. } \\
\text { "When I started working back in the '70s at my first } \\
\text { waitressing job, I could pay for a bus pass with just half } \\
\text { a day's work. But now I got to do more than a day's } \\
\text { shift, maybe a shift and a half, if I want to buy a pass. } \\
\text { It's just not fair anymore." } \\
\text { NDP leader Gary Doer scoffed at the Liberal proposal, } \\
\text { calling it "a cheap election gimmick." } \\
\text { Doer pointed to the NDP's website and said his party } \\
\text { has already pledged to raise the minimum wage to \$10 } \\
\text { within two years. }\end{array}$ & $\begin{array}{l}\text { aren't left behind," he said. } \\
\text { "It will be raised gradually in a way that's amenable to } \\
\text { small businesses." } \\
\text { Richard Levine, the head of the Winnipeg's } \\
\text { Antipoverty Council, said he welcomes any increase to } \\
\text { the minimum wage. } \\
\text { But boosting the wage rate is only a first step in } \\
\text { alleviating the city's poverty problems, he added. } \\
\text { "Vulnerable people are falling through the cracks all } \\
\text { the time," he told The Sun. "A fairer wage will help } \\
\text { some people, but it won't do much to get people off the } \\
\text { streets or help feed and shelter the elderly." } \\
\text { Manitoba needs a major reinvestment in its social } \\
\text { safety net, he said. }\end{array}$ & $\begin{array}{l}\text { ends meet. } \\
\text { McFadyen said he wants to see the basic personal } \\
\text { exemption increase by } \$ 600 \text { by } 2011 \text {. That would } \\
\text { remove } 12,000 \text { low-income Manitobans from the tax } \\
\text { roll, he estimated. } \\
\text { "The easiest way to eliminate poverty is by removing } \\
\text { the obstacles to success. And we all know what those } \\
\text { obstacles are - a high tax rate and government } \\
\text { interference." }\end{array}$ \\
\hline
\end{tabular}

Figure 1. Example Campaign Article

Finally, after reading the articles and voting, subjects completed a post-treatment questionnaire in which we measured attention to the campaign, recall of the policy promises in the campaign, the success of our manipulations, and our dependent variable, satisfaction with democracy. Our question is identical to the question used in many cross-national surveys: "On the whole, are you very satisfied, fairly satisfied, not very satisfied, or not at all satisfied with the way democracy works in Canada?" (dichotomized in the analysis, with $1=$ satisfied with democracy).

The experimental manipulation follows a 3X4 factorial design where we presented the same information — the entire set of news articles — to all subjects in the same sequence with two exceptions. First, we manipulated the result of the election so that either the centre-left NDP or the centre-right Liberal party won a majority or minority government. From this manipulation we can create measures 
for election winners and losers. We expect subjects who won the simulated campaign (Winners), based on their vote choice, to be more satisfied with democracy after controlling for their pre-treatment characteristics if our authority hypothesis is supported (Hypothesis 1).

Second, we manipulated whether the environment was discussed as an issue in the campaign. As an experiment conducted in a single national setting, we cannot manipulate system-level variables like institutions. So, we manipulate a mechanism - the presence of voice as operationalized by discussion in the course of the campaign of an issue our respondents' care about. The voice of these subjects was represented in coverage by either environmental advocacy groups or the Green Party, depending on the condition. These political actors were selected because it is likely that citizens only feel their voice on issues is adequately represented when the voice-representatives are ones that would face significant costs for deviating from their preferences. In this case, Green parties and environment groups stake their credibility on their articulation of environmental concerns and their pursuit of pro-environment public policy unlike other political actors. Our design includes conditions that distinguish between interest group and political party voices to enable us to assess whether effects of voice require a party with seats in the legislature. This assures us that our findings speak broadly to the effect of voice on satisfaction with democracy and are not merely function of the number of parties. This led to the randomized presentation of three distinct campaigns:

1) A four-party campaign with the Conservative, Liberal, NDP, and Green parties taking policy positions that correspond to their real-world locations. ${ }^{11}$ We call this the "Green party" condition. Policy issues raised in this condition were law and order, workfare, the minimum wage, and the environment.

\footnotetext{
11 We carefully validated the party placements with another set of subjects. This indicated that our articles were indeed communicating policy differences on a left-right spectrum as we intended. Details available on request.
} 
2) A three-party campaign identical to the one in the Green party condition but without the Green party. Instead, various interest groups, especially environmental ones, expressed the same points of view - usually in the same language - as the Green party in the four-party campaign. We call this the "Environmentalist" condition.

3) A three-party campaign where environmental issues were not discussed and the two explicitly environmental articles were replaced with two articles on the issue of support for culture and the arts. This is the "Control" condition.

Table 1. Experimental Conditions

\begin{tabular}{|c|c|c|c|c|}
\hline $\begin{array}{c}\text { Issue } \\
\text { Representation }\end{array}$ & \multicolumn{4}{|c|}{ Control (Arts) } \\
\hline Election Result & $\begin{array}{c}\text { NDP- } \\
\text { Majority }\end{array}$ & $\begin{array}{c}\text { NDP- } \\
\text { Minority }\end{array}$ & $\begin{array}{c}\text { Liberal- } \\
\text { Minority }\end{array}$ & $\begin{array}{c}\text { Liberal- } \\
\text { Majority }\end{array}$ \\
\hline $\begin{array}{c}\text { Issue } \\
\text { Representation }\end{array}$ & \multicolumn{4}{|c|}{ Environmentalist } \\
\hline Election Result & $\begin{array}{c}\text { NDP- } \\
\text { Majority }\end{array}$ & $\begin{array}{c}\text { NDP- } \\
\text { Minority }\end{array}$ & $\begin{array}{c}\text { Liberal- } \\
\text { Minority }\end{array}$ & $\begin{array}{c}\text { Liberal- } \\
\text { Majority }\end{array}$ \\
\hline $\begin{array}{c}\text { Issue } \\
\text { Representation }\end{array}$ & \multicolumn{4}{|c|}{ Green party } \\
\hline Election Result & $\begin{array}{c}\text { NDP- } \\
\text { Majority }\end{array}$ & $\begin{array}{c}\text { NDP- } \\
\text { Minority }\end{array}$ & $\begin{array}{c}\text { Liberal- } \\
\text { Minority }\end{array}$ & $\begin{array}{c}\text { Liberal- } \\
\text { Majority }\end{array}$ \\
\hline
\end{tabular}

The experimental conditions are shown in Table 1. We expect subjects to be more satisfied with democracy in the Environmentalist and Green party conditions if our voice hypothesis is supported (Hypothesis 2). Our primary interest is in whether discourse can improve democratic satisfaction and we do not have strong expectations about whether the effect of discourse on satisfaction with democracy would matter more when issue concerns were represented by a political party. If subjects derive satisfaction from hearing their voice represented in discourse, it follows that institutions that facilitate voice, like electoral systems, the media, regulation of the media, interest group access to political elites, and campaign finance law, may have important effects on satisfaction with democracy 
independent of policy outcomes with implications that stretch beyond explaining cross-system differences in satisfaction with democracy. Finally, we also expect the importance of voice to be conditional on authority (Hypothesis 3). That is, we expect stronger effects of voice among election losers if hearing one's issues is less important for citizens that vote for the party that forms the government.

The design has two distinctive and related features that combine to provide, in our view, an exceptional degree of correspondence with the real-world conditions pertinent to the subjects-a property that has major benefits with respect to external validity (Gaines, Kuklinski, and Quirk 2006). First, taking advantage of some relatively distinctive features of Canadian elections and party systems, we presented campaigns that featured different subsets of the same parties that the subjects engage with in their real-world life as citizens. Fortunately, most Canadians in a given province do not closely follow politics in other provinces, especially the smaller provinces. Yet, they are exposed to occasional news from other provinces, with enough variation in electorally competitive parties to make any subset of the four parties plausible as a general matter. Our manipulation of the presence of the environment as an issue and the Green party in the campaign are both plausible for Canadians facing a simulated election in another province since the Green party has been very inconsistently present in provincial politics over the last two decades, while discussion of environmental issues has waxed and waned over the last three decades. We were thus able to manipulate basic features of the party system and election discourse while keeping the elections, from a subject's standpoint, completely realistic.

Second, we assiduously maintained this realism in the presentation of policy positions and other information from the campaign. Many election experiments present brief, stylized, and highly simplified representations of political actors' policy or ideological positions-making a vivid impression of their differences essentially inescapable for subjects. Although these designs have advantages, any expectations of external validity require strong assumptions about which features of 
campaign activity capture voters' attention and affect decisions. In contrast, our design presents subjects with a series of full-length newspaper stories that include rich detail on campaign events and rigorously realistic statements of issue positions.

This use of simulated campaign materials that closely resemble real media coverage has significant implications for the study. On one hand, it should promote greater engagement by subjects and lead them to respond much as they would to a real-world campaign. On the other hand, this design dilutes the influence of our treatments by exposing subjects to extensive, potentially distracting 'filler' material that is identical across treatments. Thus the impact of the manipulations of policy in the campaign depends, as in real-world politics, on the efforts and ability of people to notice them, amid the complexities of concrete issues and the cacophony of a campaign.

Our concerns are therefore the opposite of those frequently considered in political psychology where the artificial treatments are often so strong as to have dubious external validity. Here, our belief is that the simulated campaign is sufficiently realistic, with so much information distracting from the treatments, that observing significant effects would be strong evidence that these attitudes are indeed affected by the character of political dialogue.

Further, our focus on realism ensures that campaign discourse is far from the deliberative democratic ideal. Justifications are rather superficial, little mutual respect is signalled, and the competitive nature of the campaign ensures there is no consensus building. This will limit the degree to which subjects view their voice as affecting democratic practice, as per Warren (1996). Any treatment effects found in this context can be seen as conservative estimates on the possible gains in democratic satisfaction that a deeper and more inclusive discourse could provide.

Because the study is situated in the Canadian context, we cannot manipulate system-level variables, of course. Instead, as we suggested above, we seek to establish a mechanism that may link electoral systems, and other institutions with implications for voice, to democratic satisfaction. So, we 
manipulate the number and political identities of voices presented in the media's coverage of a campaign. We do not have strong expectations about whether treatments similar to ours would have similar effects among subjects in non-majoritarian systems. We might expect similar findings because the simulated campaign divorces the treatments from policy implications. There is also little reason to expect variation in the treatment effect across electoral systems caused by the existence or nonexistence of a non-electoral actor like interest groups articulating a position. And, if there are crosssystem differences in treatment effects, it is not clear in which direction they would fall. On the one hand, the higher stakes of SMP systems may swamp the influence of voice. On the other hand, if postelection dialogue and governance is more inclusive in non-majoritarian systems due to coalition dynamics, perhaps subjects in these contexts would be less responsive to the campaign-related discourse featured in these experiments.

More fundamentally, we really aim only to show that when there is variation in the breadth and inclusiveness of voices, citizens are more satisfied. Since, as democratic theorists have shown, voice and representation are essential components of a healthy democracy, we expect that there is variance in voice within systems for various reasons - including simple temporal variation - so the effect we demonstrate is important within polities as well as across them.

\section{Data}

Our experiments were conducted on two distinct samples. Because it would be impractical to present experimental manipulations of the prominence of issues for many different issues, we required a set of subjects who could be assumed to care strongly about one particular issue. The issue chosen was the environment and we went looking for groups who would likely care strongly whether this issue, and their policy preferences on it, gets a hearing in an election campaign. In other words, we 
targeted the environmentalist issue public (Converse 1964). We have little reason to expect that our findings would not apply to other issue publics as well.

In the first study, conducted in 2015, subjects were undergraduate students enrolled in political science classes at the University of British Columbia in Vancouver, Canada, who participated in exchange for course credit. We are confident that students care enough about the environment to be considered part of its broader issue public. In similar undergraduate student subject pools used for different studies, the environment, on average, was ranked the most important issue out of a list of ten salient topics in Canadian politics, such as security and terrorism, debt and deficits, immigration and refugees, and electoral reform. The relatively high salience of the topic is combined with a distinctive set of preferences that are similar to those of environmentalists. When asked to provide their preferred rate for a tax on carbon dioxide, on a scale of 0 to 100 dollars, only 3 percent of the sample opposed a tax outright, with a median value of 40 dollars per tonne. ${ }^{12}$

Nevertheless, we were not confident that the students we surveyed exhibited the same intensity on environmental issues as an issue public more narrowly conceived, so our second study involves the same experiment run on card carrying environmentalists. To do this we collaborated with the Sierra Club of Canada (SCC), a prominent, membership-based organization focused specifically on environmental issues. SCC members were invited to do our survey through the organization's email newsletter, with a direct appeal from the director. The incentive was collective: they were told that if we received 500 valid responses, the SCC would receive a payment of $\$ 3000$, so subjects were not personally rewarded for participation. In the end, we received 1,474 valid responses from SCC members. We are confident that these subjects do care strongly about the environment. The mean

\footnotetext{
12 As points of comparison, in 2016 Canada set a national target of 10 dollars per tonne to rise to 50 dollars per tonne by 2022, and British Columbia's pioneering carbon tax is currently set at a rate of 30 dollars per tonne.
} 
Green Party feeling thermometer in the SCC subjects is 74, whereas it is 55 among the student subjects and only 44 for respondents to the Canadian Election Study in the same year (2015). Further, much like our student sample, only 4 percent of the SCC sample opposed a price on carbon, but the median preferred tax was modestly higher (50 dollars per tonne).

Our hypotheses also depend on the assumption that the environment is more important to the subjects than arts and culture. For the second set of subjects, members of the Sierra Club of Canada, this is unproblematic. For the students, we know from close proximity that political science undergraduates are generally much more concerned with environmental issues than with government support for arts and culture. But we made sure by giving a list of 14 issues and asking the student subjects to drag the ones they "care about strongly" into a box and then rank them. Environment was selected by $62 \%$, while arts and culture was picked by $34 \%$. Only six percent chose arts and culture but not environment. The environment appeared in the top four issues for $51 \%$ of those who picked it, while it was only in the top four issues for $7.6 \%$ of those that said they cared about arts and culture. We are confident that, in the aggregate, our student subjects care much more about discussion of environmental issues than discussion of support for arts and culture. In total, our experiments were run on 456 undergraduate students and 1474 members of the Sierra Club of Canada who gave a valid answer to the satisfaction with democracy question.

We must have confidence that subjects attended to the series of news articles in a manner broadly comparable to that of actual voters in real elections in order to generalize from our findings to the effects of party systems in real-world election campaigns. After the campaign we presented subjects with a screen showing 16 issues and asked them to click all the issues that were discussed in the campaign. By this measure, the manipulations were extremely successful. For issues that were not varied by condition there are no significant differences across a comparison of the control vs the environmental conditions. For arts and culture, which replaced the environment articles in the control 
condition, $88 \%$ of those in that condition said it was discussed, as compared with just 1 percent in the other two conditions. In the environmental conditions, by contrast, 91 percent said the environment was discussed, as compared with 24 percent in the non-environment condition. For climate change the difference was 61 percent to 8 percent. Based on these variables, we defined a variable indicating successful treatment - having noticed that the environment was an issue discussed in the campaign which identified $86 \%$ of students as being correctly treated, and $93 \%$ in the Sierra Club sample.

Second, we wanted to know if subjects had noticed the election result. We asked at the end how much influence each party would have on policies until the next election, measured on a 0-4 scale. Among student subjects, the mean expected Liberal influence across the Liberal majority, Liberal minority, NDP minority, and NDP majority conditions was 3.2, 2.9, 2.2, and 2.1 and almost exactly the same means in reverse order for the NDP; the Conservatives appropriately had greater expected influence in both minority-government conditions, and the Greens were expected to have much more influence in the NDP minority condition than any other. Clearly, these subjects noticed, in the last of eight full-length newspaper articles, which party had won. The same pattern holds with the Sierra Club sample with a mean Liberal influence of $3.4,3.1,2.1$, and $2 .^{13}$

Subjects also engaged at a gut level with the campaign. We asked subjects: "How do you think you would feel if you had been through this campaign and gone out and voted for real?” In the student study, among those who voted for the party that won the election, only $6 \%$ were on the dissatisfied side, while among everyone else fully 54\% were dissatisfied. The same pattern held in the Sierra Club sample, where only $10 \%$ of election winners were dissatisfied with the campaign, compared with $68 \%$

\footnotetext{
${ }^{13}$ In the Sierra Club study we used two screener questions as recommended by Berinsky and his colleagues (2014). Over three-quarters of subjects passed both tests, and only $6 \%$ failed both. Results are not materially different when excluding subjects who failed the screener tests.
} 
for everyone else. We are confident that the subjects in both samples took the treatment and, in a very realistic sense, experienced this campaign.

Importantly, our dependent variable, the satisfaction with democracy question, does not reference Manitoba or the simulated election; it is a general question about satisfaction with how democracy works in Canada. Our expectation, put simply, is that when these subjects hear environmental issues discussed, they will be more positive about democracy than when that same fraction of campaign time is spent discussing government support for arts and culture.

\section{Results}

We treat the three hypotheses in order. Were winners, even in this simulated campaign, more satisfied than losers, as we expect in Hypothesis 1? If they were not, our ability to generalize from these findings would be weak. Because the election result - a Liberal or NDP win - was varied independently of the voicing of issues, we define winners as those subjects who got an election result where the party they voted for won either a majority or a minority government status. Respondents who were undecided were removed from the analyses.

Election winners were indeed more satisfied with democracy in both samples. Among students, 76 percent of subjects who lost the simulated campaign said they were satisfied with Canadian democracy, versus 87 percent of winners. ${ }^{14}$ This difference of 11 points is impressive and significant $(\mathrm{p}<0.01)$. Among Sierra Club members, 18 percent of subjects who lost the election were satisfied with democracy, compared with 23 percent of those who won. This difference of five points is also significant ( $p \sim 0.04)$. While the differences on Hypothesis 1 are fairly modest, recall that this is a simulated campaign over a roughly twenty-minute experiment in a province the respondents do not

\footnotetext{
${ }^{14}$ Plots of the unconditional proportions of subjects satisfied with democracy in each condition can be found in Figures A16-A18 in the Appendix.
} 
reside in. We take this as good evidence that some of the winner-loser gap in observational studies does derive from the feeling of being on the winning side, since these subjects are fully aware that the simulated election has no consequences for policy.

Hypothesis 2 expects satisfaction to be lower in the control than in the environmental issue conditions. ${ }^{15}$ Students have much higher overall levels of satisfaction than Sierra Club members, but the difference between the control and environmental issue conditions is slight. 77 percent of students are satisfied with democracy in the control condition, compared with 79 percent in the environmental issue conditions, which is not statistically significant $(\mathrm{p} \sim 0.48)$. There is more evidence of a difference between conditions among environmentalists. 18 percent of environmentalists are satisfied with democracy in the control condition versus 23 percent in the environmental issue conditions ( $\mathrm{p} \sim 0.04)$. In at least the Sierra Club sample, satisfaction with democracy is higher when issues that subjects value are part of political discourse - even after mere exposure to a simulated campaign from another province.

The most important finding of this study, however, is in support for Hypothesis 3 . We have to account for the fact that we do not technically manipulate winning and losing the election - we manipulate the result. Our moderating variable is thus, in part, observational. Losing our simulated campaign is correlated with other factors that may also be related to one's satisfaction with democracy, such as voting for the Green party. The nature of our manipulation ensures that Conservatives always lose the simulated election and Greens always lose in the Green party condition. This latter point is particularly problematic in the Sierra Club sample with its unusually high proportion of Green partisans (32 percent) who have lower levels of pre-treatment efficacy than other respondents. Once

15 There were no significant differences in treatment effects between the two variants of the environmental condition. Analyses using each condition separately can be found in Table A1 in the Appendix, with predicted probabilities in Figure A19. 
they go from being a mix of winners and losers in the control and Environmentalist conditions to automatically losers in the Green party condition, it may create an abnormally low satisfaction score in the Green party condition among losers, and a high satisfaction score among winners in the same condition. This suggests the need to control for party identification and ideology. It is also possible that people who lose the simulated campaign may be systematically less efficacious before treatment. We thus control for pre-treatment efficacy that is measured with a question asking respondents whether they believe their views are represented in politics on a four point scale.

Table 2. Logistic Regression Estimates

\begin{tabular}{|c|c|c|c|c|c|c|}
\hline & \multicolumn{3}{|c|}{ Students } & \multicolumn{3}{|c|}{ Sierra Club } \\
\hline & 1 & 2 & 3 & 1 & 2 & 3 \\
\hline \multirow[t]{2}{*}{ Environment Treatment } & 0.12 & 0.16 & $0.66^{*}$ & $0.30^{* *}$ & $0.34^{*}$ & $0.66^{* * *}$ \\
\hline & $(0.28)$ & $(0.32)$ & $(0.39)$ & $(0.15)$ & $(0.18)$ & $(0.26)$ \\
\hline \multirow[t]{2}{*}{ Winner } & $0.75^{* * *}$ & $0.61 *$ & $1.68^{* * *}$ & $0.32 * *$ & $0.44 * * *$ & $0.88^{* * *}$ \\
\hline & $(0.29)$ & $(0.33)$ & $(0.62)$ & $(0.14)$ & $(0.17)$ & $(0.30)$ \\
\hline \multirow[t]{2}{*}{ Treatment * Winner } & & & $-1.59 * *$ & & & $-0.64 *$ \\
\hline & & & $(0.73)$ & & & $(0.36)$ \\
\hline \multirow[t]{2}{*}{ CPC PID } & & -0.04 & -0.02 & & -0.15 & -0.16 \\
\hline & & $(0.55)$ & $(0.55)$ & & $(0.46)$ & $(0.47)$ \\
\hline \multirow[t]{2}{*}{ NDP PID } & & $-0.72^{* *}$ & -0.69 & & -0.20 & -0.19 \\
\hline & & $(0.36)$ & $(0.36)$ & & $(0.22)$ & $(0.22)$ \\
\hline \multirow[t]{2}{*}{ Green PID } & & 0.96 & 1.03 & & $-0.88^{* * *}$ & $-0.92 * * *$ \\
\hline & & $(1.15)$ & $(1.15)$ & & $(0.25)$ & $(0.25)$ \\
\hline \multirow[t]{2}{*}{ No PID } & & -0.10 & 0.01 & & $-0.83^{* * *}$ & $-0.85^{* * *}$ \\
\hline & & $(0.52)$ & $(0.52)$ & & $(0.31)$ & $(0.32)$ \\
\hline \multirow[t]{2}{*}{ Ideology } & & 0.09 & 0.11 & & $0.27 * * *$ & $0.28 * * *$ \\
\hline & & $(0.09)$ & $(0.09)$ & & $(0.05)$ & $(0.05)$ \\
\hline \multirow[t]{2}{*}{ Efficacy, Pre-Treat } & & $0.88^{* * *}$ & $0.92 * * *$ & & $0.52 * * *$ & $0.52 * * *$ \\
\hline & & $(0.25)$ & $(0.26)$ & & $(0.11)$ & $(0.11)$ \\
\hline Constant & $1.08^{* * *}$ & -0.56 & -1.09 & $-1.69 * * *$ & $-2.77 * * *$ & $-3.00 * * *$ \\
\hline Pseudo R2 & 0.02 & 0.08 & 0.10 & 0.02 & 0.10 & 0.11 \\
\hline $\mathrm{N}$ & 373 & 321 & 321 & 1249 & 1049 & 1049 \\
\hline
\end{tabular}

We thus estimate three models for each sample using logistic regression. The first model estimates the effects of our environmental issue conditions and winning the election on satisfaction with 
democracy. The second model adds in controls for party identification, ideology, and pre-treatment efficacy. The third model adds an interaction between the election result and the environmental issue conditions, as per Hypothesis 3. The results are shown in Table 2.

Model 1 shows that among students election winners are significantly more satisfied with democracy than losers (Winner, $\mathrm{p} \sim 0.01$ ). However, there is no significant difference in satisfaction between those exposed to the environmental issue conditions and those in the control condition (Environmental Treatment, $\mathrm{p} \sim 0.67$ ). These results remain after adding control variables in model 2 . We can calculate predicted probabilities from the estimates of model 2 to provide a more substantive interpretation to these results. Those who won the election are 9 points more likely to be satisfied with democracy than losers (86/77 percent). In contrast, subjects exposed to the environmental issue treatments are expected only to be two points more likely to be satisfied with democracy than those in the control condition (81/79 percent).

A different picture emerges when considering the moderating (interactive) influence of the election result in model 3. We see now that our environmental issue treatments have an effect in the expected (positive) direction, but only among election losers (Environmental Treatment, p 0.09). In contrast, the environmental issue conditions are associated with slightly lower satisfaction with democracy scores among election winners, but this is not statistically significant ( $\mathrm{p} \sim 0.14)$. The key indicator is that the interaction term is significant (Treatment * Winner, $\mathrm{p} \sim 0.03$ ), indicating that the winner-loser gap shrinks when the campaign deals with issues that our subjects care about. Predicted probabilities are displayed in the left panel of Figure 2 to more clearly illustrate the effects. The estimates from model 3 suggest that among losers, subjects in the environmental issue conditions were 11 points more likely to be satisfied with democracy compared with those in the control condition (80/69 percent). This narrowed the winner-loser gap in satisfaction with democracy, which declined from 23 points $(92 / 69$ percent) in the control condition to 2 points $(82 / 80$ percent) in the 
environmental issue conditions. Hearing about an issue our subjects care about leads to a convergence in satisfaction with democracy between election losers and winners, just as the macro-level observational literature shows. And recall that the dependent variable is general satisfaction with democracy; the question was not about this campaign or this election or democracy in Manitoba.
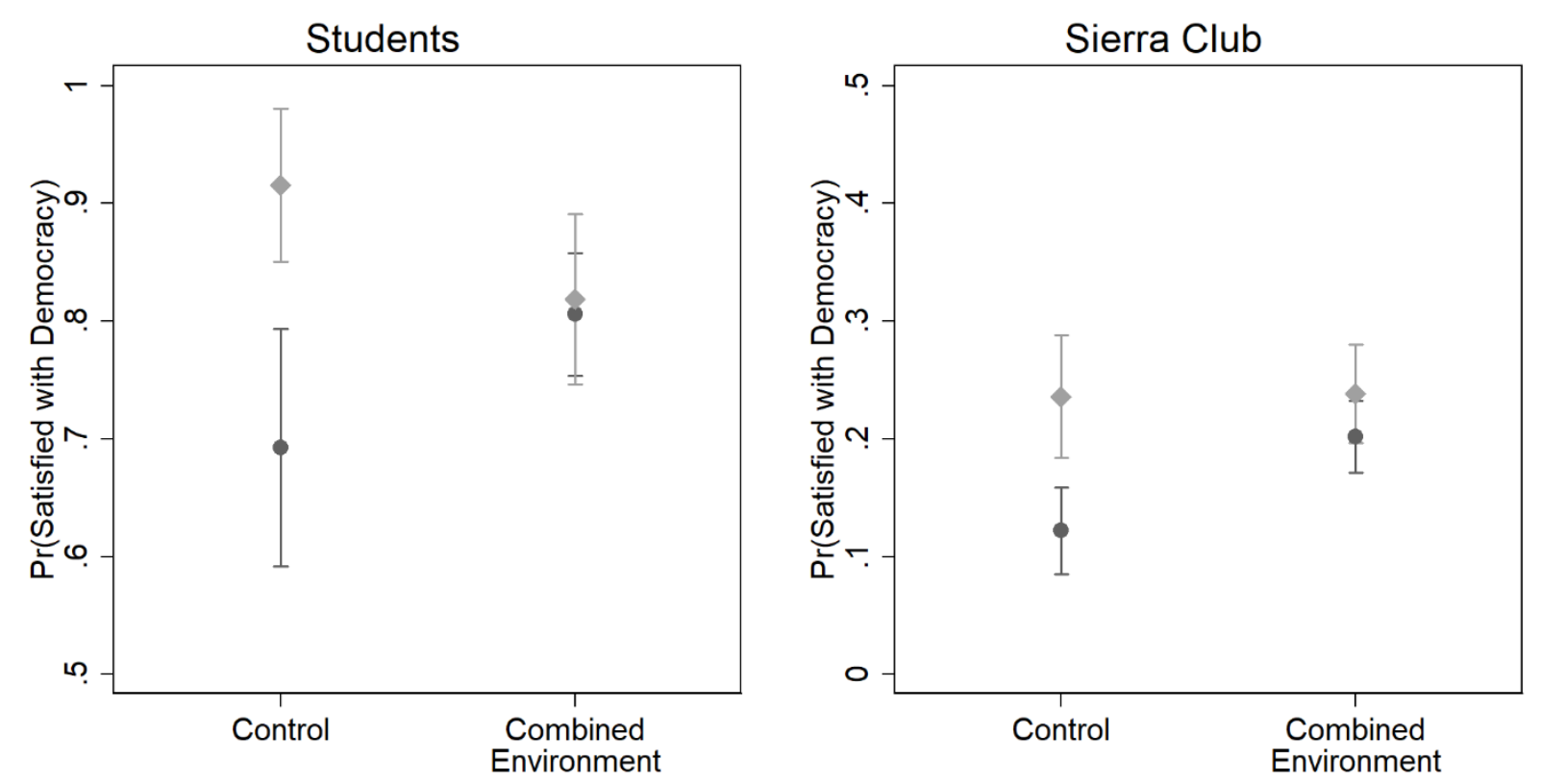

- Loser $\diamond$ Winner

Figure 2. Predicted probabilities for Model 3 in the student (left) and Sierra Club (right) samples. Note: Error bars reflect $90 \%$ confidence intervals

Results are clearer for Sierra Club members, as we should expect because of greater concern for the issue. Model 4 shows that election winners are significantly more satisfied with democracy than losers (Winner, $\mathrm{p} \sim 0.02$ ). Additionally, those in the environmental issue conditions were more satisfied with democracy than those in the control condition (Environmental Treatment, $\mathrm{p} \sim 0.05$ ). Effects are modestly stronger when controls are added in model $5(\mathrm{p}<0.01 \& \mathrm{p} \sim 0.06)$. Predicted probabilities were generated based on the estimates for model 5. Election winners were 6 points more likely to be 
satisfied with democracy than losers (24/18 percent), and those in the environmental issue conditions were 5 points more likely to be satisfied with democracy (22/17 percent).

Model 6 shows an interactive effect similar to the student sample. The environmental issue treatment effects are only significant for those who lost the election (Environmental Treatment, $\mathrm{p} \sim 0.01$ ). There is no such relationship among election winners. The interaction term is significant (Treatment* Winner, $\mathrm{p} \sim 0.08)$, indicating that the gap between winners and losers shrinks when exposed to environmental discussion. The predicted probabilities in the right panel of Figure 2 more clearly illustrate the effects. The estimates from model 6 suggest that among election losers, subjects in the environmental issue conditions were 8 points more likely to be satisfied with democracy compared to those in the control condition (20/12 percent). This reduced the winner-loser satisfaction with democracy gap from 12 points in the control condition (24/12 percent) to 4 points in the environmental issue conditions (24/20 percent). The story, much like for the student sample, is that hearing about the environment in the treatment conditions leads to convergence in satisfaction with democracy between winners and losers. ${ }^{16}$

The generalizability of these findings is bolstered by the fact that these effects are present among relatively satisfied students and among environmentalists who are sour on Canadian democracy. These latter people are, in general, left-leaning, affluent, educated citizens, and yet they are by-and-large dissatisfied with Canadian democracy. Most likely, they were fed up with the Conservative government

\footnotetext{
${ }^{16}$ We might expect to find a stronger distinction between winners and losers in majority government conditions. Minority governments rarely last a full legislative term and they tend to be characterized by cooperation between the government and one or more opposition parties. This may cushion the effect of losing, and limit the interactive effect found. Analysis presented in the Appendix shows that the majority-minority difference only inconsistently manifests itself. In our student sample, there was no difference. Among environmentalists the effects were slightly stronger in the minority condition. Results can be found in Table A2, and marginal effects are presented in Figures A20 and A21.
} 
that had been in office for nine years at the time of the experiment. So, even among these hard cases, as long as they see their concerns articulated in a simulated provincial election campaign, and despite their preferred party losing that election, they are significantly less dissatisfied with democracy when that issue is discussed.

\section{Discussion}

There is undoubtedly more to citizen satisfaction with democracy than the ephemeral feeling of winning or losing. Citizens do, of course, feel better about how their democracy works when their preferred party or candidate is in office. Some of the winner-loser gap in satisfaction must be emotional, as our results for Hypothesis 1 suggest, and some of it surely reflects instrumental concerns for policy close to one's ideal point. But the balance of these factors probably matters little because concerns about the health of democracy focus instead on electoral losers: those who may feel inadequately represented and who get policies that they oppose. Naturally, then, scholars have wondered whether there are institutional factors - electoral systems, number of parties in government, alternation in power, and so on - that can dampen losers' dissatisfaction with the system. In broad strokes, scholars have found that institutions associated with non-majoritarian democracy have this effect, in contrast to the institutions of more majoritarian systems (Anderson and Guillory 1997; Lijphart 1999). But, it is not yet clear what, of the many differences between these systems, causes the observed differences in satisfaction between them. By implication, it is not clear what citizens value about their democracies.

We find that even a very general system-level attitude like "satisfaction with how democracy works" is amenable to experimental manipulation. We emphasize that although the experimental treatment effects in this paper are not large, the experiments we report are not typical in political science where artificially strong treatments are often used with few or no potential distractions and 
with dependent variables tied closely to the treatments. Instead, our treatments were realistically complicated and diffuse, while our dependent variable asked about democracy in general, not about the simulated campaign to which subjects were exposed. ${ }^{17}$

Our finding in this experiment is that when citizens have the sense that their positions on issues that are important to them are being discussed - merely discussed - they are modestly more positive about the entire democratic political system. When their issues are ignored, they are more dissatisfied. Furthermore, the presence of dialogue on salient issues affects satisfaction more strongly among election losers. The clear implication, but one that we do not test in any way in the present paper, is that consensus and non-majoritarian democracies may help close the winner-loser gap with more inclusive and wide-ranging political dialogue. So, then, may other institutions that facilitate a broader and more inclusive elite political discourse within any of these political systems.

Our findings that show the importance of voice or dialogue are more credible because they align so closely with the conclusions of the many observational studies. To some extent, it is something about the political discourse - the voices - in more consensual or non-majoritarian systems that affect satisfaction with democracy, and not just the larger proportion of winners or the greater number of

\footnotetext{
${ }^{17}$ In the post-treatment questionnaire we asked respondents whether they believed important issues were addressed in the campaign. We would expect our treatment to influence this variable if there truly is an effect of the treatment on SWD. Table A3 in the Appendix shows that respondents are more likely to say important issues were addressed in the campaign when exposed to discussion of the environment. We also asked respondents whether they believed people like themselves had a say in what government does. This is not an ideal measure because it is unclear why discussion of the environment by environmentalists or the Green Party (who doesn't form government) would affect their perceived influence on government. However, it may tap into underlying efficacy and can serve as a robustness check. The results, presented in Table A2, show the effect holds only for students.
} 
voters included in the governing coalitions. Sartori (1976) and other scholars may have been right when they that suggested a number-of-parties effect was, in fact, about the airing of concerns.

We started our experiments with an undergraduate student sample under the expectation the environment is an important issue for most of them. We were correct, but lacked confidence in generalizing these findings to more typical issue publics in the general population. So, we surveyed environmentalists as well. We see no reason to expect that our findings would not travel to other issue publics. Because the environment receives frequent media coverage, if anything we may expect even stronger effects for issues that are regularly ignored but are important to certain groups of voters.

Finally, as noted above, we did not believe that these treatment effects would vary much across electoral system contexts, and two findings reinforce this judgment. First, the treatment condition featuring environmentalists worked as well, if not better than the condition featuring the Green party (see Table A1 and Figure A19 for these analyses). There is clearly something about the voice itself that matter to respondents. It is not clear why we would expect subjects in non-majoritarian systems to respond differently to the media presence of interest groups they are aligned with. Second, the environmental issue treatment effects were not stronger among those in the majority outcome condition, and if anything, they were weaker in our sample of environmentalists. The more inclusive cooperation among parties that sometimes (but not always) characterizes minority governments and their coalition government counterparts in non-majoritarian settings did not diminish the effects of issue inclusion on satisfaction with democracy.

The evidence provided by our experimental study and its observational counterparts suggest that those worried about the 'democratic deficit' should not just pay attention to electoral systems, but to other, more changeable, institutions as well. While electoral systems do indeed strongly influence the number of parties, and particularly the presence of parties trumpeting single issues that might be ignored in smaller party systems, other features of political systems may also have important effects 
on satisfaction because of their impact on democratic discourse. An important future research agenda would inquire as to the links between these institutional features and satisfaction with democracy.

The experimental approach used here can be transported into other institutional and issue contexts for greater external validity, while new manipulations could shed light on how different features of political discourse are related to satisfaction with democracy. For one example, as Reher (2014) shows, satisfaction with democracy could increase simply by elevating the salience of issues people care about independent of whether a certain issue position is reflected in discourse. Our experiment does not provide a clean test of this proposition because respondents see both their issue and issue position reflected in the simulated election campaign. For another example, it may also be interesting to manipulate other indicators of discourse quality to determine their effect on satisfaction with democracy, such as justification quality, displays of mutual respect, and consensus building to provide a bridge to the important work done by democratic theorists. There is still much we do not know about citizen satisfaction with democracy. We hope that well-crafted experimental manipulations can provide an important contribution as the research program moves forward.

\section{References}

Aarts, Kees, and Jacques Thomasson. 2008. "Satisfaction with Democracy: Do Institutions Matter?" Electoral Studies 27: 5-18.

Althaus, Scott, Jill A. Edy, Robert M. Entman, Patricia Phalen. 1996. "Revising the Indexing Hypothesis: Officials, Media, and the Libya Crisis.” Political Communication 13(4): 407-21.

Anderson, C. J. 2012. "How Electoral Systems Shape What Voters Think About Democracy." Presented at the conference on "Duty and Choice: Participation and Preferences in Democratic Elections", Montreal, QC. 
Anderson, Christopher J., and Christine A. Guillory. 1997. "Political Institutions and Satisfaction with Democracy: A Cross-National Analysis of Consensus and Majoritarian Systems." American Political Science Review 91(1): 66-81.

Anderson, Christopher J., Andre Blais, Shaun Bowler, Todd Donovan, and Ola Listhaug. 2005. Losers' Consent: Elections and Democratic Legitimacy. New York: Oxford University Press.

Banducci, Susan A., Jeffrey A. Karp. 2003. "How Elections Change the Way Citizens View the Political System: Campaigns, Media Effects and Electoral Outcomes in Comparative Perspective.” British Journal of Political Science 33 (3): 443-67.

Bennett, W. Lance. 1988. News: The Politics of Illusion (2nd ed.). New York: Pearson Longman.

Berggren, Heidi, Gregory A. Fugate, Robert R. Preuhs, and Dennis R. Still. 2004. "Satisfied? Institutional Determinants of Citizen Evaluations of Democracy." Politics \& Policy 32(1): 72-97.

Berinsky, Adam J., Michele F. Margolis, and Michael W. Sances. 2014. "Separating the Shirkers from the Workers? Making Sure Respondents Pay Attention on Self-Administered Surveys." American Journal of Political Science 58(3): 739-53.

Bernauer and Vatter 2012. "Can't Get No Satisfaction with the Westminster Model? Winners, Losers, and the Effects of Consensual and Direct Democratic Institutions on Satisfaction with Democracy." European Journal of Political Research 51: 435-68.

Blais, Andre, and Francois Gélineau. 2007. "Winning, Losing, and Satisfaction with Democracy." Political Studies 55 (2): 425-41.

Budge, Ian, and Dennis Farlie. 1983. Explaining and Predicting Elections: Issue Effects and Party Strategies in Twenty-Three Democracies. London: Allen \& Unwin.

Bühlmann, Marc, Wolfgang Merkel, Lisa Müller, and Bernhard Weßels. 2012. "The Democracy Barometer: A New Instrument to Measure the Quality of Democracy and its Potential for Comparative Research.” European Journal of Political Science 11(4): 519-36. 
Diamond, Jared. 2005. Collapse: How Societies Choose to Fail or Succeed. New York: Viking Press.

Celis. Karen. 2006. “Substantive Representation of Women: The Representation of Women's Interests and the Impact of Descriptive Representation in the Belgian Parliament (1900-1979).” Journal of Women, Politics \& Policy 28(2): 85-114.

Chambers, Simone. 2003. "Deliberative Democratic Theory." Annual Review of Political Science 6(1): 30726.

Chang, Eric, Yu-han Chu, and Wen-chin Wu. 2014. "Consenting to Lose or Expecting to Win? InterTemporal Changes in Voters' Winner-Loser Status and Satisfaction with Democracy." In Jacques Thomassen, ed. Elections and Representative Democracy: Representation and Accountability. Oxford: Oxford University Press.

Cohen, Joshua. 1989. "Deliberation and Democratic Legitimacy." In Alan Harmlin and Philip Petit, eds. The Good Polity. Oxford: Blackwell.

Converse, Philip E. 1964. “The Nature of Belief Systems in the Mass Public.” In David E. Apter, ed. Ideology and Its Discontents. New York: The Free Press of Glencoe.

Curini, Luigi, Willy Jou, and Vincenzo Memoli. 2012. "Satisfaction with Democracy and the WinnerLoser Debate: The Role of Policy Preferences and Past Experience.” British Journal of Political Science 42: 241-61

Curini, Luigi, Willy Jou, and Vincenzo Memoli. 2015. Why Policy Representation Matters: The Consequences of Ideological Congruence between Citizens and their Governments. London: Routledge.

Dryzek, John. 2010. Foundations and Frontiers of Deliberative Governance. Oxford: Oxford University Press. Esaiasson, Peter 2011. "Electoral Losers Revisited: How Citizens React to Defeat at the Ballot Box." Electoral Studies 30: 103-13.

Ezrow, Lawrence. 2007. “The Variance Matters: How Party Systems Represent the Preferences of Voters." Journal of Politics 69(1), 182-92. 
Ezrow, Lawrence, and Georgios Xezonakis. 2011. “Citizen Satisfaction with Democracy and Parties' Policy Offerings.” Comparative Political Studies 44(9), 1152-78

Fung, Archon, and Erik Olin Wright. 2003. Deepening Democracy: Institutional Innovations in Empowered Participatory Governance. London: Verso Books.

Gaines, Brian, James H. Kuklinski, and Paul J. Quirk. 2006. "The Logic of The Survey Experiment Reexamined.” Political Analysis 15(1): 1-20.

Gilens, Martin. 2015. "Descriptive Representation, Money, and Political Inequality in the United States.” Swiss Political Science Review 21(2): 222-28.

Golder, Matt, and Jacek Stramski. 2010. "Ideological Congruence and Electoral Institutions.” American Journal of Political Science 54(1): 90-106.

Habermas, Jurgen, 1996. Between Facts and Norms: Contributions to a Discourse Theory of Law and Democracy. Cambridge: MIT Press.

Han, Sung Min, and Eric C. Chang. 2016. "Economic Inequality, Winner-Loser Gap, and Satisfaction with Democracy." Electoral Studies 44: 85-97.

Henderson, Ailsa. 2008. "Satisfaction with Democracy: The Impact of Winning and Losing in Westminster Systems.” Journal of Elections, Public Opinion and Parties 18(1): 3-26.

Kuyper, Jonathan W. 2016. "Systemic Representation: Democracy, Deliberation, and Nonelectoral Representatives." The American Political Science Review, 110(2): 308-324.

Lijphart, Arend. 1999. Patterns of Democracy. New Haven: Yale University Press.

Nyblade, Benjamin. 2004. "The "Effective" Number of Issue Dimensions: A Measure with Application to West Europe." Paper presented at the Midwest Political Science Association National Conference, Chicago, IL.

Petrocik, John R. 1996. "Issue Ownership in Presidential Elections, with a 1980 Case Study." American Journal of Political Science 40: 825-50. 
Petrocik, John R., William L. Benoit, and Glenn J. Hansen. 2003. "Issue Ownership and Presidential Campaigning, 1952-2000.” Political Science Quarterly 118: 599-626.

Preuhs. Robert R. and Eric Gonzalez Juenke. 2011. "Latino U.S. State Legislators in the 1990s: Majority-Minority Districts, Minority Incorporation, and Institutional Position.” State Politics \& Policy Quarterly 11(1): 48-75.

Rehr, Stefanie. 2015. "Explaining Cross-National Variation in the Effect of Priority Congruence on Satisfaction with Democracy.” European Journal of Political Research 54(1): 160-81.

Sartori, Giovanni. 1976. Parties and Party Systems: A Framework for Analysis. New York: Cambridge University Press.

Saward, Michael. 2006. “The Representative Claim”. Contemporary Political Theory 5: 297-318.

Singh, Shane. 2014. "Not all Election Winners are Equal: Satisfaction with Democracy and the Nature of the Vote." European Journal of Political Research 53(2): 308-27.

Singh, Shane, Ekrem Karakoç, and Andre Blais. 2012. "Differentiating Winners: How Elections Affect Satisfaction with Democracy.” Electoral Studies 31: 201-11.

Steiner, Jürg, André Bächtiger, Markus Spörndli, and Marco R. Steenbergen. 2005. Deliberative Politics in Action: Analyzing Parliamentary Discourse. Chapel Hill: University of North Carolina Press.

Stoll, Heather. 2008. "Dimensionality and the Number of Parties in Legislative Elections." Party Politics 17(3): 405-27.

Warren, Mark. 1996. "Deliberative Democracy and Authority." American Political Science Review, 90: 4660.

Warren, Mark. 2017. "A Problem-Based Approach to Democratic Theory.” American Political Science Review, 111(1): 39-53.

Washington. Ebonya. 2012. “Do Majority-Black Districts Limit Blacks' Representation? The Case of the 1990 Redistricting." Journal of Law \& Economics 55(2): 251-74. 
